
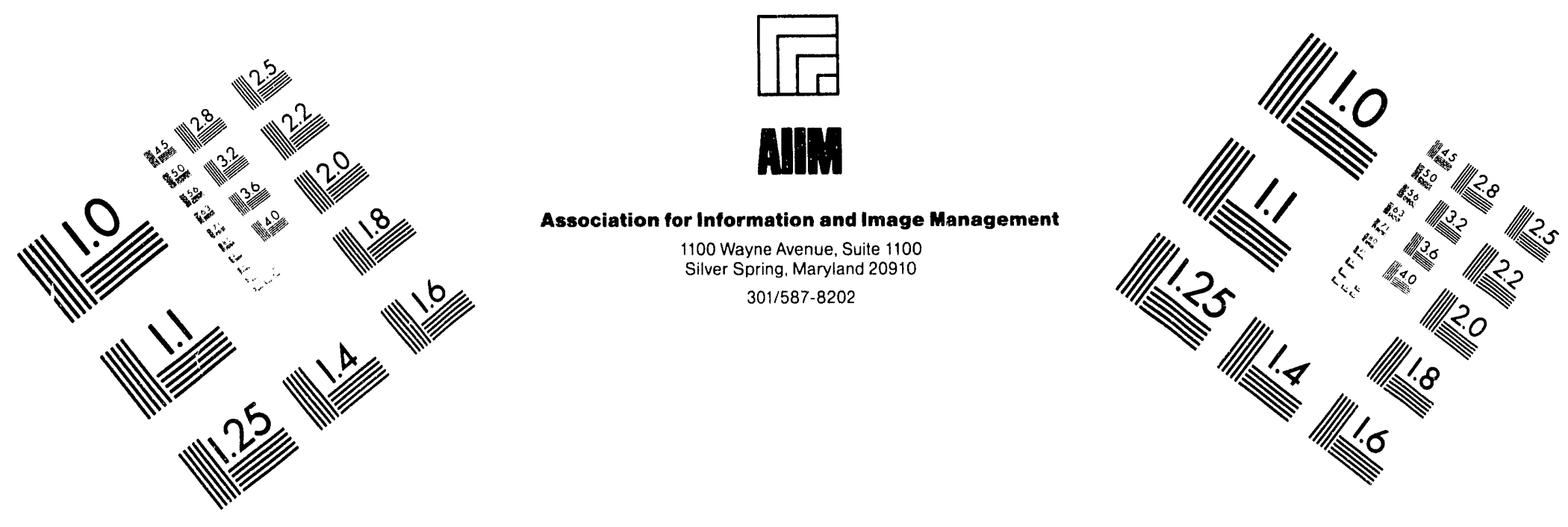

\title{
Centimeter
}

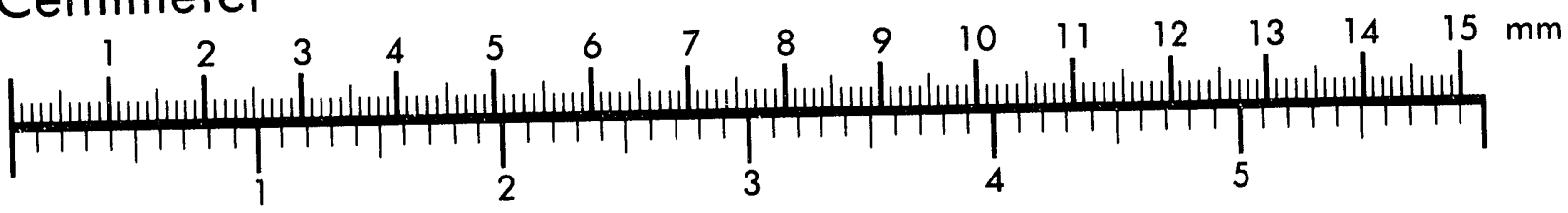
Inches
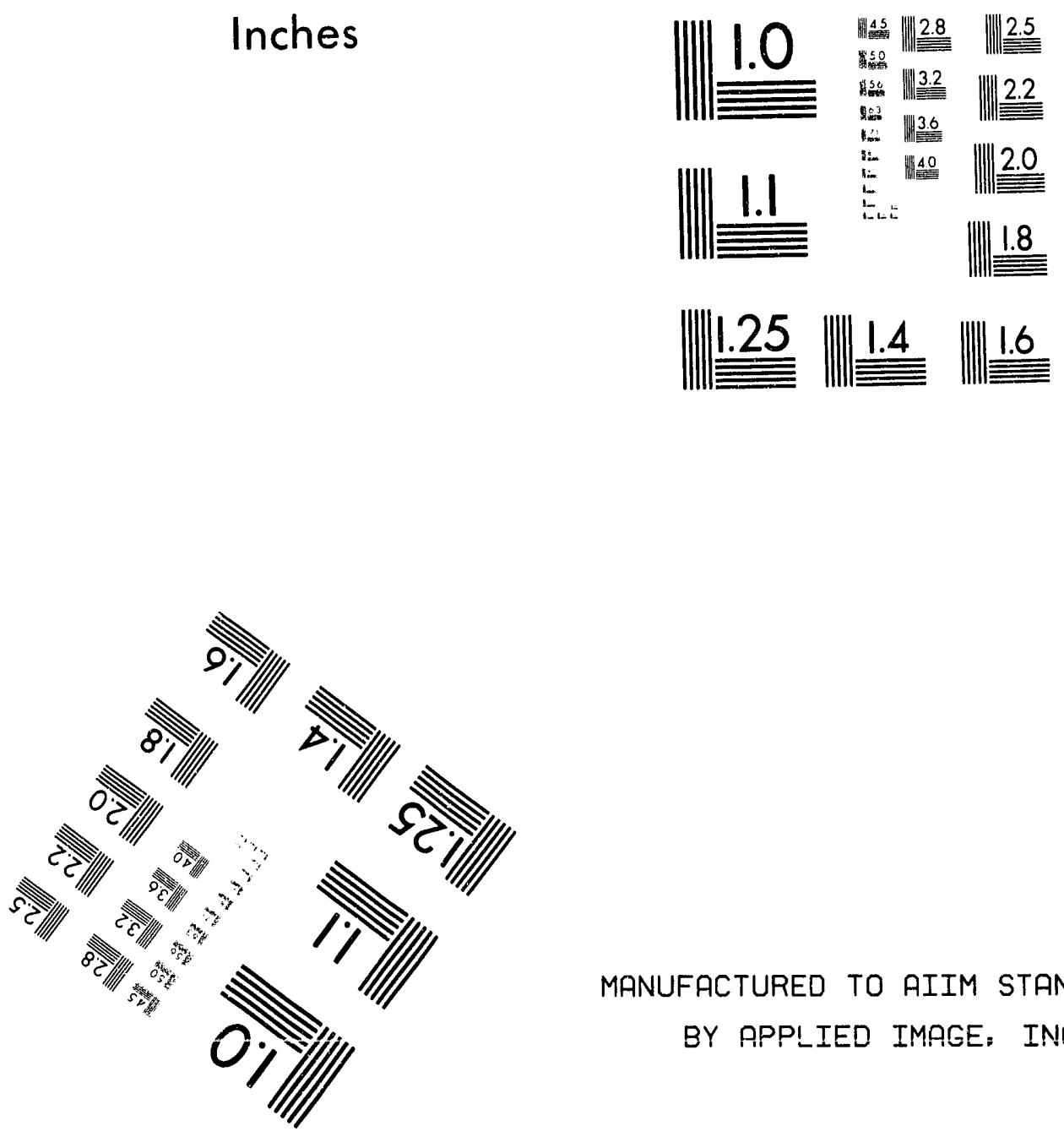

MANUFACTURED TO AIIM STANDARDS

BY APPLIED IMPGE: INC.

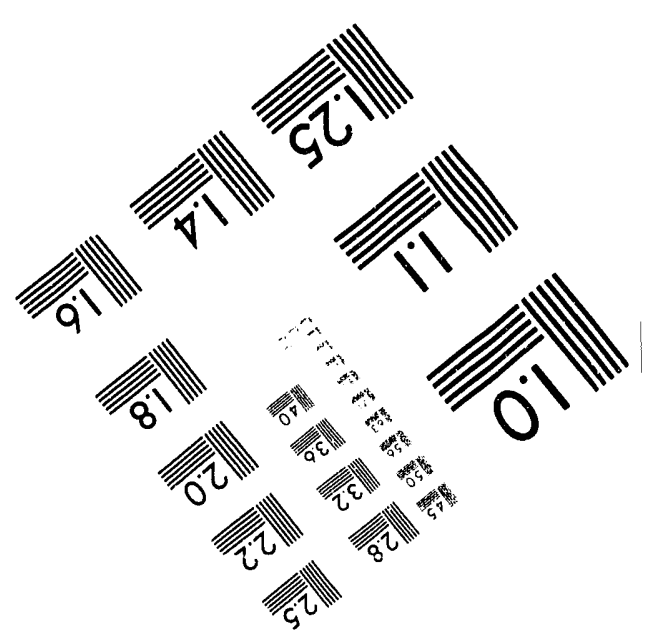



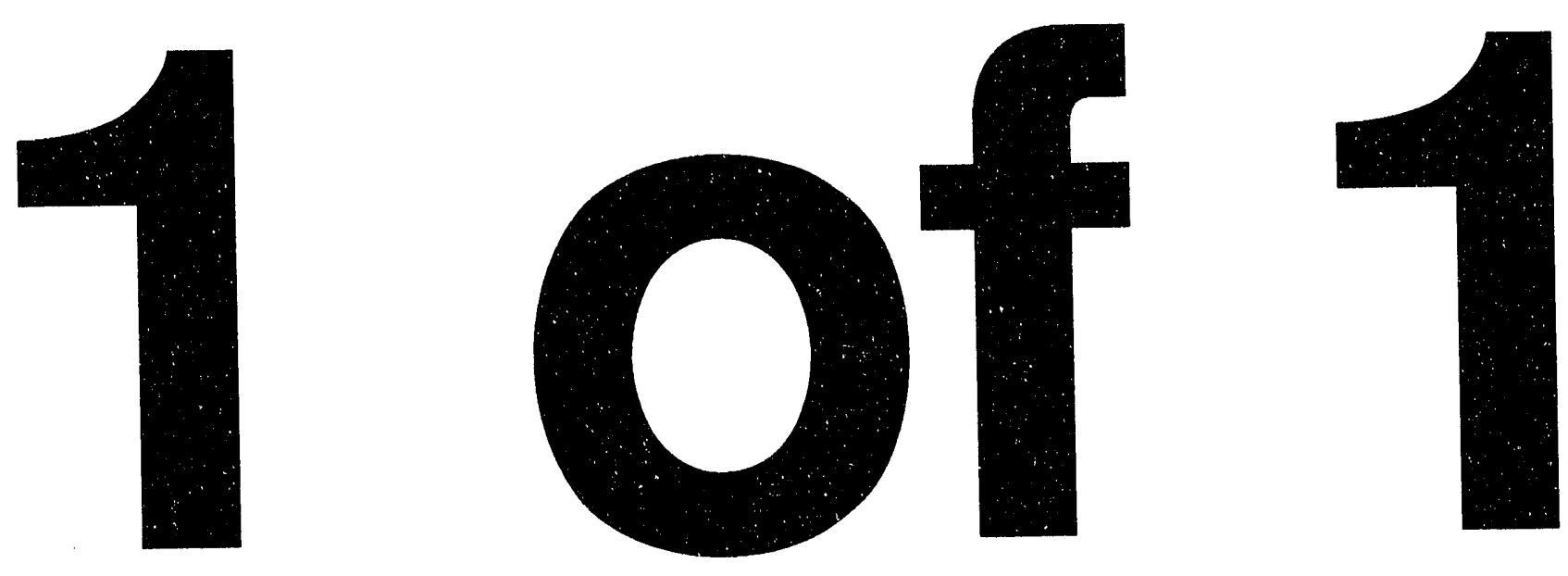


$$
\text { DOELCH/10324. T/6 }
$$

Southern State Radiological Transportation Emergency Response Training Course Summary

September 1990

Southern States Energy Board 
This report was prepared as an account of work sponsored by an agency of the United States Government. Neither the United States nor any agency thereof, nor any of their employees, nor any of their contractors, subcontractors, or their employees, makes any warranty, expressed or implied, or assumes any legal liability or responsibility for the accuracy, completeness, or usefulness of any information, apparatus, product, or process disclosed, or represents that its use would not infringe any privately owned right. Reference herein to any specific commercial product, process, or service by trade name, trademark, manufacturer, or otherwise, does not necessarily constitute or imply its endorsement, recommendation, or favor by the United States Government or any agency thereof. The views and opinions of authors expressed herein do not necessarily state or reflect those of the United States Government or any agency thereof.

The Southern States Energy Board (SSEB) is a public, non-profit organization created by an interstate compact. The States of Alabama, Arkansas, Florida, Georgia, Kentucky, Louisiana, Maryland, Mississippi, Missouri, North Carolina, Oklahoma, South Carolina, Tennessee, Texas, Virginia, West Virginia and the Commonweal th of Puerto Rico are members of the Board. The activities of the Board are funded by state support payments by the member states.

For more than two decades, the Southern States Energy Board has served the South with research, technical staff support, policy development and information services. SSEB's purpose is to improve the economy of the South and to contribute to the individual and community well-being of the people of the southern region. The Board assists its members in the creation of programs in energy, science and technology, environment and related areas of interest. SSEB provides a scientific and technical expertise on energy and environmental quality matters to state officials and the general public. 


\section{Southern State Radiological Transportation Emergency Response Training Course Summary}

September 1990

Prepared for the U.S. Department of Energy

under Cooperative Agreement

DE-FCO2̌-87CH 10324

by

Southern States Energy Board

3091 Governors Lakes Drive, Suite 400

Norcross, Georgia 30071

(404) 242-7712 


\section{TABLE OF CONTENTS}

Page

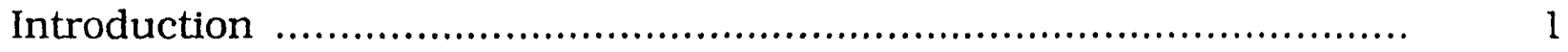

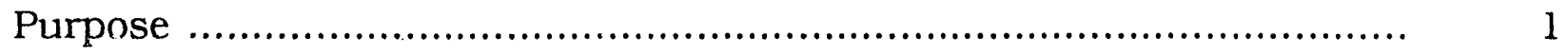

Federal Agency Course Summaries ............................................. 2

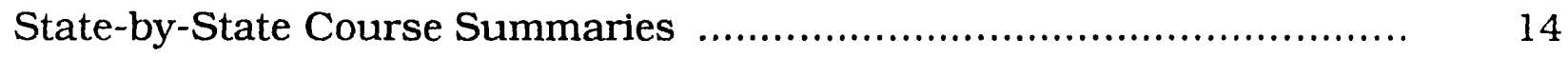

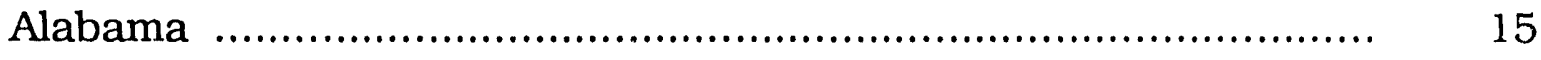

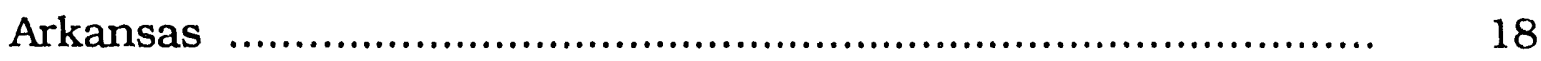

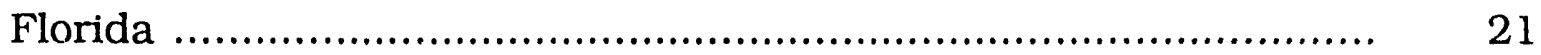

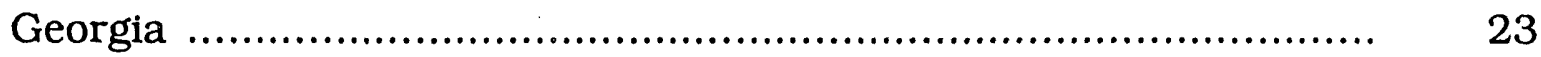

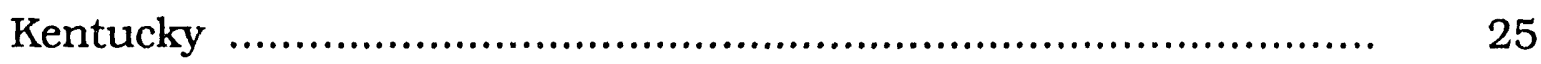

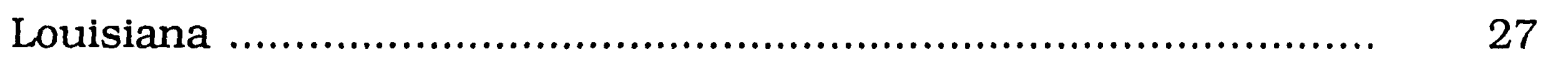

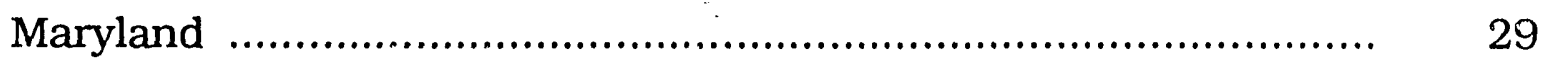

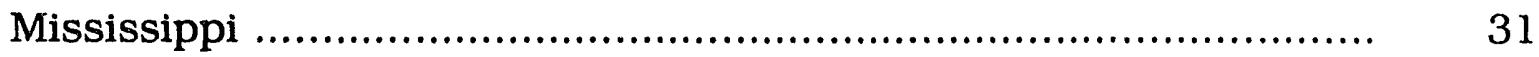

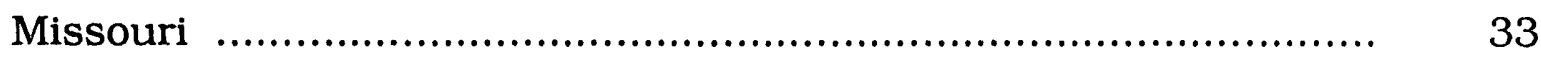

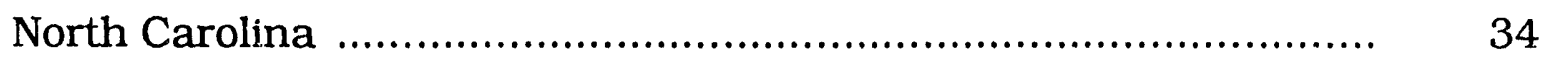

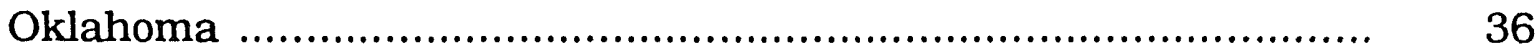

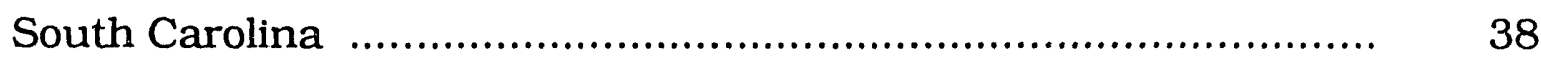

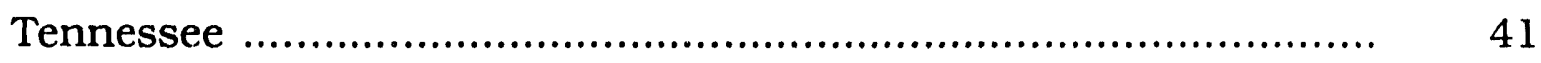

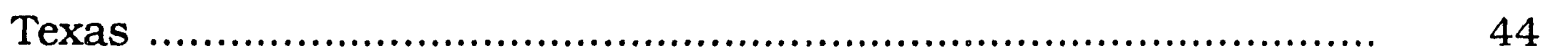

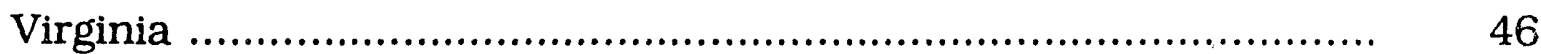

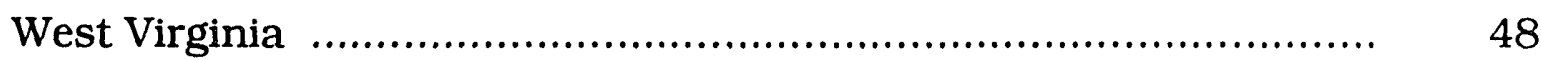

Conclusion ............................................................................... 50 


\section{INTRODUCTION}

The Southern States Energy Board (SSEB) is an interstate compact organization that serves 16 states and the commonwealth of Puerto Rico with information and analysis in energy and environmental matters. Technical support and services are offered in a variety of areas, including renewable and alternative energy technologies; energy conservation; acid rain; utility regulation; clean coal technologies and technology transfer; oil and natural gas supply; and solid, hazardous and radioactive materials management.

Nuclear waste management is a topic that has garnered considerable attention in the SSEB region in the last several years. Since 1985, SSEB has received support from the U.S. Department of Energy for the regional analysis of high-level radioactive waste transportation issues. In the performance of its work in this area, SSEB formed the Advisory Committee on High-Level Radioactive Materials Transportation, which comprises representatives from impacted states and tribes. SSEB meets with the committee semi-annually to provide issue updates to members and to solicit their views on activities impacting their respective states.

Among the waste transportation issues considered by SSEB and the committee are shipment routing, the impacts of monitored retrievable storage, state liability in the event of an accident and emergency preparedness and response. This document addresses the latter by describing the radiological emergency response training courses and programs of the southern states, as well as federal courses available outside the southern region.

\section{PURPOSE}

Section 180 (c) of the Nuclear Waste Policy Act, as amended in 1987 (NWPAA), requires the U.S. Department of Energy (DOE) to provide technical assistance and funds to states for training public safety officials of appropriate units of local government and Indian tribes through whose jurisdiction spent nuclear fuel or high-level radioactive waste will pass. 
As the department develops its plans for implementation of Section 180 (c). information on the status of state emergency preparedness and response programs is needed. Therefore, under a cooperative agreement with DOE, SSEB surveyed the southern states regarding emergency preparedness and response training and prepared this summary of state and federal courses to reflect current practices. A survey was sent to the radiological health program director in each state with a request to solicit input from other state agencies if appropriate. The survey focused on information regarding transportation accident response training. Since Puerto Rico will not be affected by transportation under the NWPA and the Amendments, information on the commonwealth's emergency preparedness and response training program is not included.

This information is not presented for evaluations of, or comparisons between and among, state programs and activities. Rather, the Southern State Radiological Transportation Emergency Response Training Course Summary is designed to provide DOE with a snapshot view of state training programs for reference as it begins to develop its assistance strategy.

\section{FEDERAL AGENCY COURSE SUMMARIES}

The federal agencies that offer radiological emergency response training are the Federal Emergency Management Agency (FEMA), DOE and the U.S. Nuclear Regulatory Commission (NRC). The U.S. Department of Transportation (DOT) assists FEMA and DOE in developing courses, but the agency alone does not sponsor emergency radiological response training courses. Most courses involving the DOT are courses involving radioactive material transportation issues.

While some courses are taught by these agencies at national and regional training centers, others are taught in the states by state emergency response with federal agency support. The following descriptions of these federal agency courses were developed using a FEMA document, Digest of Federal Training in Hazardous Materials (FEMA 134, July 1987). 


\section{Federal Emergency Management Agency (FEMA)}

\section{Radiological Training Series}

FEMA supports the development of state and local radiological emergency response capabilities through its Radiological Training Series, which is developed and taught by the Emergency Management Institute at the National Emergency Training Center in Emmitsburg, Maryland. The series comprises two fundamental courses for state and local emergency response personnel and representatives of industries or services that could have a role in response.

\section{Radiological Emergency Preparedness Planning Course}

Federal, state and local government and nuclear utility personnel involved in radiological emergency preparedness planning participate in this five-day training course. The curriculum includes hazards analysis, off-site monitoring and instrumentation, protective actions, regulatory considerations, planning policies and criteria exercises and media public relations. There are no tuition or registration fees for this course. Travel expenses are paid for by the individual states on a reimbursement basis. Free overnight lodging is available at the Emittsburg Training Center dormitories.

Fundamentals Course for Radiological Response Teams/Radiological Officers Train-the-Trainer (Radiological Instructor Course III)

This one-week train-the-trainer course is designed to qualify instructors to teach the Fundamentals Course for Radiological Response Teams, the Fundamentals Course for Radiological Officers and the Radiological Monitor Instructor Course. There are no tuition charges or registration fees. Travel expenses, including mileage and meals, are reimbursed and free overnight lodging is available at the Emmitsburg Training Center dormitories. 


\section{Field Courses}

In addition to the training courses offered at the training center in Emmitsburg, Maryland, FEMA and other federal agencies join together to sponsor training courses within the states. These courses, called "field courses", are taught in the states by state emergency response personnel with federal agency support. Funding for these courses is provided through FEMA's Emergency Management Training Fund.

\section{Fundamentals Course for Radiological Monitors (FCRM)}

Federal, state and local emergency services personnel and volunteers serving as radiological monitors comprise the target audience for this two-day course. The FCRM, taught by local radiological management instructors at local emergency management centers, focuses on fundamentals of radiation, radiological hazards, radiological instruments, radiation protection principles and monitoring techniques and protective actions. A four-hour refresher course is also offered. There are no tuition or registration fees for this course. Travel expenses, including mileage, overnight lodging and meals, are paid for by each individual state, up to limits allowed by state law.

\section{Fundamentals Course for Radiological Response Teams (FCRRT)}

Over a five-day period, local radiological response teams receive instruction on radiological emergencies, radiaticin fundamentals, biological effects and risks. monitoring instruments, exposure and contamination control and hazard assessment. Trained radiological response team members receive a two-day refresher course. No tuition or registration fees apply. Travel expenses are paid by the states, up to allowance limits.

\section{Fundamentals Course for Radiological Officers (FCRO)}

The FCRO includes a radiological response team review exercise and instruction in responsibilities of the radiological officer, instrumentation and response planning, managing a radiological protection system and source handling techniques. The five-day course is designed for state and local 
radiological officers in program management. A three-day refresher course is also offered. There are no tuition or registration charges, and travel expenses are paid by the individual states.

\section{Radiological Monitor Instructor Course (RMIC)}

This three-day course is available to instructors of the Fundamentals Course for Radiological Monitors and the Aerial Radiological Monitoring Course. Training topics include recruiting and scheduling, instructional techniques and methodology, expedient radiological training, radiation source set handling techniques, review of FCRM modules and microteaching. Tuition and registration fees are not charged. Travel expenses, including overnight lodging, mileage and meals, are paid by individual states.

\section{Hospital Emergency Department Management of Radiation Accidents}

This one-day overview of radiation and emergency care of radiation accident victims is taught by state emergency management agencies to physicians, nurses and other medical personnel. The course emphasizes organization of the radiological emergency response team, facility and staff preparation, patient reception and triage, medical and decontamination procedures, contamination control, radiological monitoring, bioassay sampling, patient transfer and post emergency activities. Tuition and registration fees are not charged. Travel expenses, including overnight lodging, mileage and meals, are paid by individual states.

\section{Radiological Emergency Preparedness Planning Course}

Federal, state and local government and nuclear utility personnel involved in radiological emergency preparedness planning participate in this five-day training course. The curriculum includes analysis of radiological hazards, off-site monitoring and instrumentation, protective actions, regulatory considerations, planning policies and criteria, exercises and media and public relations. There is no charge for tuition or registration. Each state reimburses travel expenses, including mileage and meals, and free overnight lodging is available at the Emmitsburg Training Center dormitories. 
Fundamentals Course for Radiological Response Teams/Radiological Officers Train-the-Trainer (Radiological Instructor Course III)

This one-week train-the-trainer course is designed to qualify instructors to teach the Fundamentals Course for Radiological Response Teams (FCRRT), the Fundamentals Course for Radiological Officers (FCRO) and the Radiological Monitor Instructor Course (RMIC). There is no charge for tuition and registration. Each state reimburses travel expenses, including mileage and meals, and free overnight lodging is available at the Emmitsburg Training Center dormitories.

\section{Federal Emergency Management Agency/U.S. Department of Energy}

\section{Radiological Emergency Response Operations Course}

The Federal Emergency Management Agency and the U.S. Department of Energy join to deliver this eight and one-half day course at the Nevada Test Site near Las Vegas, Nevada. Attendees primarily comprise members of state and local radiological emergency response teams. Federal government and private industry participation is authorized on a limited basis. Course topics include proper response techniques and management of radiological incidents, including use of portable radiation instruments, evaluation of instrument readings, area control and team response.

Several exercises expose students to various potential emergency situations. In a transportation exercise, teams respond to a vehicle accident involving radiopharmaceutical wastes and toxic chemicals. The simulated accident is accompanied by fire and injuries.

According to the registrar at the National Emergency Training Center, the Radiological Emergency Response Operations (RERO) course has been cancelled for the remainder of FY90 due to insufficient funds. A decision on the FY91 schedule for the RERO course, which is generally offered monthly, will be made in August 1990. 
First Response to Transportation Emergencies Involving Radioactive Materials

The Federal Emergency Management Agency, the U.S. Department of Energy and the U.S. Department of Transportation have developed a ten-hour (five cassette) video course on first response to radioactive material transportation accidents. There are no tuition or registration fees for this course. States pay for travel expenses.

\section{Aerial Radiological Monitoring Course}

The Aerial Radiological Monitoring Course provides on-the-ground training in the devices and mechanisms used on helicopters for radiation detection and monitoring. Although it is a part of the course curriculum, few states offer in-flight training. Instructors from the Civil Air Patrol teach the course to state personnel from various agencies, using instruments and course materials supplied by FEMA. There is no charge for tuition, and the same rules for travel expenses apply to this course as with all other state-sponsored FEMA field courses.

\section{Principal Contact:}

Barbara Hickson - Registrar

Emergency Management Institute

National Emergency Training Center

16825 S. Seton Avenue

Emmitsburg, Maryland 21727

(301) $447 \cdot 1084$

\section{U.S. Department of Energy}

The U.S. Department of Energy offers training courses at the Radiation Emergency Assistance Center/Training Site (REAC/TS) in Oak Ridge, Tennessee. DOE and FEMA provide funding to implement these courses. There are no tuition charges, only registration fees, which vary from course to course. Travel expenses are paid by the employer. 
In addition, a DOE contractor, Science Applications International Corporation, offers a workshop and a seminar on radioactive materials transportatior. These are taught at various locations around the country.

Lastly, DOE's WIPP Project Office offers the States Training and Education Program to future transuranic waste shipment corridor states. Six courses are available; five are taught in the corridor states and one is taught at REAC/TS.

\section{Medical Planning and Care in Radiation Aiccidents}

State and local health officers and physicians who provide services to the nuclear industry participate in this one-week course. Topics covered in the training include fundamentals of radiation and radiology, radiation detection and measurement, care of radioactively contaminated patients and acute radiation symptoms. There is a $\$ 90.00$ registration fee.

\section{Health Physics in Radiation Accidents}

This one-week course is designed for health physicists who may assist in the medical aspects of radiological emergency response. Areas addressed in the training are radiation physics, radiation detection and internal dosimetry, protective clothing and equipment and the role of the health physicist in the medical environment. The registration fee is $\$ 90.00$.

\section{Handling of Radiation Accidents by Emergency Personnel}

Emergency room physicians and nurses who may be called upon to treat a radiation accident victim atterd this three and one-half day course. Students learn the fundamentals of radiation and methods of detecting and measuring radiation, preventing the spread of contamination and reducing radiation doses to the victim and attending personnel. The registration fee is $\$ 75.00$. 


\section{Qccupational Health in Nuclear Facilities}

A five-day course intended for physicians, nurses and others who provide occupational health care to employees of government nuclear industries. This course presents information on basic radiation sciences, health surveillance and evaluations, on-site emergency management of injuries and medical implications of chemical, physical, biological, social and phychological stresses on the ability to work. Additional topics include inter-department relationships and medical, legal and ethical issues of concern to health professionals in nuclear facilities.

The registration fee is $\$ 90.00$. Travel expenses, including mileage, meals and overnight lodging, is paid for by the specific employer.

\section{Principal Contacts:}

Robert Ricks, Ph.D.

Director, REAC/TS

P.O. Box 117

Oak Ridge, Tennessee 37831-0117

(615) 576-3131.
Martha Payne

Registrar, REAC/TS

P.O. Box 117

Oak Ridge, Tennessee 37831-0117

(615) 576-3131.

The following courses are taught by a DOE-sponsored group, Science Applications International Corporation, at various locations around the country.

\section{Radioactive Material Transportation Basic Workshop}

DOE primarily provides this four-day course for its employees and contractor traffic departments. State and local government personnel can participate on a space-available basis. The workshop reviews information on hazardous and radioactive materials regulations and transportation orders. There are no tuition or registration expenses, and overnight lodging is the responsibility of each individual or group attending the course. 


\section{Radioactive Material Orientation Seminar}

This eight-hour seminar offers federal, state and local government personnel a general overview of radioactive material shipment, regulations, enforcement, DOE operations, public concerns and emergency response. No tuition charges or registration fees apply. Travel expenses are the responsibility of each indiviciual or group attending the course.

\section{Principal Contact:}

Teresa Yearwood

Science Applications International Corporation

P.O. Box 2501

Oak Ridge, Tennessee 37831

(615) 482-9031.

\section{States Training and Education Program}

In anticipation of the shipment of transuranic waste from $10 \mathrm{DOE}$ facilities across the nation to the Waste Isolation Pilot Plant (WIPP) in Carlsbad, New Mexico, DOE is offering six courses to state and local personnel along planned shipment routes. The courses include an eight-hour First Responder Course, a four-hour Refresher Course, a twelve-hour Train-the-Trainer Course, which is designed to teach state-certified instructors techniques used in the First Responder Course, a sixteen-hour Command and Control Course, a 4-hour Mitigation Course and an eight-hour Medical Management in Radiation Accidents Course taught by REAC/TS. To date, these courses have been offered in the states along the corridor from the Savannah River Site to the WIPP site, which are South Carolina, Georgia, Alabama, Mississippi, Louisiana and Texas.

The First Responder Course has attracted the largest number of students. It is intended for the first arriving emergency units (fire, medical, law enforcement, and rescue), who may be working without a formal incident command system initially and without health physics professionals to guide them. Course topics include a basic WIPP overview, an explanation of radiation and radiation protection 
principles, transportation regulations, the TRANSCOM satellite tracking system, package design, emergency response actions at the accident scene and DOE's emergency response and cleanup role.

The First Responder Refresher Course target audience is first responders who either attended the First Responder Course or the Command and Control Course. It is designed to reacquaint students with the WIPP project and to reinforce radiation protection principles and response protocol. The course includes updated information about the project, such as draft land withdrawal legislation, the standard waste box. TRUPACT certification and shipping schedules. The main objective with the refresher course is to reinforce the students' knowledge of emergency procedures.

The 12-hour Train-The-Trainer Course is presented to a class of ten to fifteen students. Students attending this course must be certified as instructors within their state or local jurisdiction. The First Responder Course is presented the first day. One the second day, the WIPP instructor will explain training materials and the lesson plan structure. In addition, answers to the most commonly asked questions will be provided. Each organization providing students will receive a copy of the First Responder Course lesson plan and 35mm slides about WIPP that can be integrated into their existing radioactive/hazardous materials training programs.

The Command and Control Course is intended for those individuals who will be either overall or partially in charge at the scene of a WIPP-related accident. Course length may be extended, at the request of a state, to discuss the specific application of a state response plan to a WIPP accident. Course topics include material discussed in the First Responders Course plus a detailed discussion of the Incident Command System. Successful completion of this course would provide the incident or scene commander with knowledge to safely respond, establish command and protect the public and the environment.

The Mitigation Course is designed for state health, safety, environmental, and radiological professionals with radiological monitoring and assessment responsibility. Within the scope of the First Responder and Command and Control Courses, students are taught actions that firefighters, law enforcement and medical personnel have performed at the accident scene. The coordination of 
local, state and federal resources is discussed with an emphasis on defining the roles and responsibilities of each of these groups. DOE's resources for supplementing state and local government radiological monitoring and assessment activities are also discussed, as well as the agency's role as the shipper. Other topics include a WIPP overview, the hazards of transuranics, TRANSCOM, the package and its contents (by generator site), the role of the medical community and alpha monitoring techniques.

The U.S. Department of Energy has contracted with REAC/TS personnel for instruction of the course on Medical Management in Radiation Accidents. The course, like the others offered by DOE, is taught in the states. The eight-hour course is available to medical personnel who may be called upon to provide emergency care to a radiation accident victim. The practical aspects of handling a contaminated victim are emphasized through discussions of the fundamentals of radiation, including how to detect and measure it, how to prevent the spread of contamination, how to reduce the radiation dose to the victim and attending personnel and the role of the medical/health physicist in caring for contaminated accident victims. The course is also open to state and industry health physics personnel who may provide assistance to hospital staff.

\section{Principal Contact:}

Steve Kouba

WIPP Project Office

Westinghouse Electric Corporation

101 Green Street

Carlsbad, New Mexico 88220

(505) 885-8883

\section{U.S. Nuclear Regulatory Commission}

\section{Protective Action Decision Making and the Role of Dose Assessment}

The U.S. Nuclear Regulatory Commission offers this one to three-day workshop to state and local protective action decision makers and their technical staffs. Nuclear power plant licensees may also participate. The training is made available by the NRC regional offices at least annually. Course topics include 
reactor systems and engineered safeguards, severe accident phenomenology, emergency planning bases, planning criteria and regulations, protective action guidelines, emergency classification/criteria, emergency action levels, protective action decision making, accident and dose assessment, source term, dispersion, dosimetry, environmental measurements, the Federal Radiological Monitoring and Assessment Center and the Federal Radiological Emergency Response Plan. A ten-week program for state health physicists is also offered. 


\section{STATE-BY-STATE COURSE SUMMARIES}




\begin{abstract}
Alabama
General Information

Transportation-Specific Training

A separate course devoted entirely to transportation is not offered at this time; however, a transportation-specific course is in the planning stages.

Transportation training is included in other courses taught by the State Health Department, and emphasis is placed upon its importance. Transportation-related subjects covered include $\mathrm{Al}$ and $\mathrm{A} 2$ values, container types, shipping labels, shipping papers, vehicle placarding and emergency response and the proper use of civil defense instrumentation.
\end{abstract}

\title{
Organizations Trained
}

The organizations and personnel that receive the training described above are the state and county health departments' environmental monitoring teams, local fire and police departments and emergency medical service personnel.

\section{Funding Sources}

Eighty percent of the funding for the state's radiological emergency response training is received from utilities that operate nuclear power plants in Alabama. The remaining 20 percent is provided by the state.

\section{Course-Specific Information}

\section{Basic Radiological Health for Environmental Monitoring Teams}

Major topics addressed in the course include basic nuclear reactor theory, radiation and its potential harm, specifics of the reactors in or near the state, the 
radiological emergency response plan, field monitoring duties and responsibilities, radio protocol, field exercises using survey meters and air monitors and response to transportation accidents.

The course is taught to approximately 10 State Department of Health personnel who are environmental monitoring team members under the state's Radiation Emergency Plan. Approximately 20 individuals at the county health department level serve as environmental monitoring team members under the Radiation Emergency Plan and participate in this course as well.

The course, which is taught over an eight-hour period, is offered once each year. Since it is offered annually, no refresher course is necessary. The Radiological Health Branch of the State Health Department is responsible for instruction.

\section{Basic Radiological Health for Fire and Police}

Major topics of this course include the definition and identification of radiation, characteristics of radiation, interactions with matter, biohazards, dose and dose rate, dose responsive curve, radioactive decay, activity, dose limits, placards and labels, transportation of radioactive materials, use of survey instruments, hot lines and contamination control and emergency medical services.

Currently, no state personnel receive this training. Rather, the course is available to local fire and police departments.

The eight-hour course was offered for the first time in January 1989. No refresher courses are planned at this time. Instruction is provided by the Radiological Health Branch of the State Health Department.

\section{Radiation Safety for Emergency Medical Services and Ambulance Personnel}

Principal topics covered in the course include fear of radiation, possible health effects, maximum allowable doses, fear of contamination and radiosuppression drugs. 
No state personnel receive this training. The course is designed for local emergency medical services and ambulance personnel.

At present, this course has been provided only once, but the state plans to offer a similar course statewide. The two to three-hour course is offered by the Radiological Health Branch of the State Health Department.

\section{Principal Contact:}

Aubrey Godwin, Director

Division of Radiological Health

Department of Public Health

State Office Building

Montgomery, AL 36130

(205) 242-5315 


\section{Arkansas}

\section{General Information}

\section{Transportation-Specific Training}

Several transportation-specific training courses are offered to and/or by the Division of Radiation Control and Emergency Management. They are as follows:

- Division training on U.S. Department of Transportation rules, regulations and procedures to respond to transportation incidents that involve radioactive material;

- DOE Hazardous Naterials Transportation Seminar with special emphasis on radioactive material shipments and first responder actions;

- Radiological Emergency Response Operations Course for Radiological Emergency Response Teams, providing an excellent overview of emergency response actions at accident sites; and

- RADEF training for defense officers and radiological response activities.

\section{Organizations Trained}

Health physicists of the Division of Radiation Control and Emergency Management receive the division's training on the U.S. Department of Transportation rules, regulations and procedures. The DOE Hazardous Materials Transportation Seminar is offered to division staff and various other state personnel who are first responders to transportation accidents. Division staff and select county officials involved in radiological emergency planning and response around Arkansas Nuclear One (power plant) receive the Radiological Emergency Response Operations Course for Radiological Emergency Response Teams. Lastly, RADEF training is available to division staff, county emergency services coordinators and local volunteers involved in the response to natural and man-made disasters. 


\section{Funding Sources}

Division training on the DOT rules, regulations and procedures is funded by the state's general revenues. For the DOE seminar on hazardous materials transportation, DOE provides funding for the course, and the state pays the salaries of division attendees. Likewise, the Federal Emergency Management Agency funds the Radiological Emergency Response Operations Course, with the state paying the salaries of division attendees. The RADEF training is funded completely by FEMA.

\section{Course-Specific Information}

\section{Division Training: Transportation Regulations and Accident Response}

This course describes the U.S. Department of Transportation regulations related to the transportation of radioactive material, with special emphasis on the labeling and posting requirements. Division policy and procedures are reviewed for transportation accidents, and table top exercises are held.

Approximately 10 individuals in the Division of Radiation Control and Emergency Management of the Arkansas Department of Health receive this training. When possible, the three-hour course is offered once a year. Division personnel within Nuclear and Environmental Safety are responsible for the training.

DOE's Radioactive Material Transportation Emergency Workshop

The workshop comprises three segments: general hazardous material transportation; radioactive material and its transportation; and radioactive incident guidelines. At the state level, approximately three individuals from the Arkansas Department of Health and two individuals from the Arkansas State Police take part in the workshop. 
At the local level, the trainee class generally comprises one representative of the Washington County Office of Emergency Services, two from the Rogers Fire Department, one from the Benton County Office of Emergency Management and one from the Yell County Office of Emergency Services.

The six-hour workshop, which is taught by DOE, is offered when deemed appropriate. No refresher courses are provided.

\section{Radiological Emergency Response Operations Course for Radiological Emergency Response Teams}

Emergency responders from Arkansas and other states travel to FEMA's course in Las Vegas, Nevada, for extensive and intensive training in responding to a wide range of radiological incidents. Basic radiation principles and ideas are taught, along with proper response protocols.

For the state of Arkansas, the primary recipient of this training is staff of the Division of Radiation Control and Emergency Management. Approximately 20 of the present staff members have taken the course since 1980. At the local level, emergency services personnel from Pope County, Arkansas, are generally sent to the course.

The course is offered yearly, and Arkansas is allowed to send up to four individuals per year to the training. Instruction lasts approximately one and one-half weeks. The course is not followed up with refresher courses. Rather, recipients receive on-the-job reviews.

\section{Principal Contact:}

Greta J. Dicus

Director, Division of Radiation Control and Emergency Management Arkansas Department of Health

4815 West Markham Street Little Rock, Arkansas 72205

(501) 661-2000 


\section{Florida}

\section{General Information}

\section{Transportation-Specific Training}

Two transportation-specific training courses are taught. One covers radiological transportation accidents specifically, while the other covers issues associated with the transportation of radioactive materials.

\section{Organizations Trained}

The recipients of the training are fire department personnel and individuals from the state's Office of Radiation Control.

\section{Funding Sources}

Funding for the state's training is provided by the Florida Power and Light Company, the Florida Power Corporation and firms that possess radioactive materials licenses.

\section{Course-Specific Information}

\section{Coping with Radiological Accidents}

General topics covered in this course include nuclear fundamentals, instrumentation, instrument use, labeling and marking of radioactive materials packages, common incidents and available assistance.

As many as 70 state Radioactive Materials and Licensing Section personnel have received the training. The course was recently offered to city and county fire personnel, with 62 people participating. 
The course is offered upon request hy the Environmental Radiation Control Section (Office of Radiation Control) of the Florida Department of Health and Rehabilitative Services. The one-day training is not followed up with a refresher course.

\section{Radioactive Materials Inspector iraining}

The course provides a broad overview of radinactive materials licensing and inspection procedures, including transportation-specific information. About 70 state radioactive materials licensing and isspection personnel have been trained. as well as ten to 12 counity lerral radiation control personnel from three agreement counties.

The three to five-day course is offered annually by the Radioactive Materials Program (Office of Radiation Control) of the Florida Department of Health and Rehabilitative Services. The course is followed up with refresher courses.

\section{Principal Contact:}

J. Daniel Nash

Manager, Radioactive Materials Program

Office of Radiation Control

Department of Health and Rehabilitative Services

1317 Winewood Boulevard

Tallahassee, Florida 32301

(904) 487-2437 


\section{Georgia}

\section{General Information}

\section{Transportation-Specific Training}

At present, the state does not offer transpcrtation-specific radiological emergency response training. The Georgia Emergency Management Agency's Radiological Emergency Preparedness Series provides training for response to an incident at a nuclear facility. In addition, GEMA offers Federal Emergency Management Agency-recognized fundamentals courses in radiological response, and state personnel participate in other courses offered by federal agencies outside the state.

\section{Organizations Trained}

A Radiation Working Group coordinates the activities of various state agencies with respect to radiological responsibilities. The agencies involved are the Georgia Emergency Management Agency, the Department of Natural Resources and the Department of Human Resources.

The Radiological Emergency Preparedness Series is taught by members of the Radiation Working Group to local police, fire, emergency medical services and rescue personnel within the 10-mile emergency planning zones of nuclear power plants in the state.

\section{Funding Sources}

Funding for radiological emergency response training is provided by FEMA and the state. 


\section{Course-Specific Information}

\section{Radiological Emergency Preparedness Series}

The series comprises several modules that can be taught separately. Series topics include an overview for decision makers, an overview of communications, field services, vehicular decontamination, reception and care and refresher training. The overview for decision makers instructs participants on power plant operations, emergency response plans and coordinated efforts in radiological emergency planning. In the field services portion, areas of study include radiation self protection, exposure control, direct radiation readings and environmental sampling. Vehicular decontamination training comprises instruction in monitoring and decontamination procedures for emergency vehicles and personnel.

\section{Principal Contact:}

James H. Wilbanks

Radiological Protection Officer

Georgia Emergency Management Agency

P.O. Box 18055

Atlanta, Georgia 30316-0055

(404) 624-7000 


\section{Kentucky}

\section{General Information}

\section{Transportation-Specific Training}

State and local personnel participate in several radiological emergency response courses held in the state and elsewhere. While none are transportation-specific, several address transportation scenarios and procedures in their curricula.

\section{Organizations Trained}

The trained emergency response personnel work in Disaster and Emergency Services, Radiation Control and local police, fire, emergency medical services and rescue units.

\section{Funding Sources}

Funding for state and local radiological emergency response training is provided by the Federal Emergency Management Agency and the state.

\section{Course-Specific Information}

\section{Emergency Preparedness Planning for a Nuclear Crisis}

This course is a home study course offered by the Federal Emergency Management Agency. Approximately 35 people request the course each year, and it requires an average of three months to complete. No refresher course is available.

The state organizations that receive this training are Disaster and Emergency Services and Radiation Control. At the local level, police, fire, emergency medical services and rescue personnel are trained. 
Fundamentals Course for Radiological Monitors

This fundamentals course is offered 10 times each year by the state Disaster and Emergency Services Area Coordinators. The course duration is 12 hours. Organizations receiving this training are Disaster and Emergency Services, Radiation Control and local police, fire, emergency medical and rescue services.

\title{
Fundamentals Course for Radiological Response Teams
}

Disaster and Emergency Services, Radiation Control, police, fire, emergency medical services and rescue personnel receive this level of training. The 32-hour course is offered annually and is followed up by an 8-hour refresher course. Disaster and Emergency Services is responsible for instruction.

\section{Fundamentals Course for Radiological Officers}

Disaster and Emergency Services, Radiation Control, police, fire, emergency medical services and rescue personnel receive this course. It is a 32-hour course that is offered biennially by Disaster and Emergency Services. An 8-hour refresher course is also offered.

\section{Radiological Monitoring Instructors Course}

Personnel from Disaster and Emergency Services, Radiation Control and police, fire, emergency medical services and rescue organizations participate in this course. Disaster and Emergency Services offers the course annually. The duration is 24 hours, and no refresher course is available.

\section{Principal Contact:}

\author{
Norma Casey \\ Emergency Operations Center \\ Disaster and Emergency Services \\ Boone National Guard Center \\ Frankfort, Kentucky 40601 \\ (502) 564-7223
}




\section{Louisiana}

\section{General Information}

\section{Transportation-Specific Training}

While the Department of Environmental Quality does not provide radiological response training to state and local personnel, staff members occasionally present lectures, using videos and slides, to fire and emergency response groups throughout the year. In addition, personnel from the state's emergency response section, who work closely with the three nuclear power plants affecting Louisiana, provide presentations on the fixed facilities using NUREG-0654 as a guide.

State personnel participate in training courses provided by federal agencies, including the Federal Emergency Management Agency's Radiological Emergency Response Operations Course and Radiological Emergency Preparedness Planning Course and the U.S. Nuclear Regulatory Commission's Protective Action Decision Making and the Role of Dose Assessment.

\section{Organizations Trained}

Health physicists from the Division of Environmental Quality receive the training offered by FEMA and NRC.

\section{Funding Sources}

Funding for radiological emergency response training is provided by FEMA and NRC. 


\section{Principal Contact:}

Stan Shaw, Ph.D.

Training Coordinator

Department of Environmental Quality

Louisiana Nuclear Energy Division

P.O. Box 14690

Baton Rouge, Louisiana 70896

(504) 925-4518 


\section{Maryland}

\section{General Information}

\section{Transportation-Specific Training}

The Maryland Department of the Environment, Office of Toxics, Environmental Science and Health, offers transportation training in its Hazardous Materials Enforcement and Compliance Course. No special funds for the training are identified.

\section{Organization Trained}

Personnel from the Department of Environment, Office of Toxics, Environmental Science and Health, receive training in addition to hazardous materials specialists within the department.

\section{Funding Sources}

No special funds for training are identified.

\section{Course-Specific Information}

\section{Hazardous Materials Enforcement and Compliance Course}

This course details the requirements of $49 \mathrm{CFR}$ and the transportation of hazardous materials. It covers the requirements for the transportation of radioactive materials, including shipping paper requirements, marking, labeling and placarding. It is taught in conjunction with the National Uniform Driver/Vehicle Inspection Course sanctioned by the U.S. Department of Transportation.

At the state level, several organizations receive this level of training. The course is taught to approximately four hazardous materials specialists in the State 
Department of the Environment who are assigned to the Motor Carrier Safety Team, 45 officers of the Maryland State Police who are assigned to the Motor Carrier Safety Team, ten Maryland Toll Facilities Police and ten Public Service Commission inspectors. Other than the four hazardous materials specialists, these personnel have very limited exposure to the transportation of radioactive materials.

At the local level, training is provided to approximately two Anne Arundel County police officers, six Baltimore County police officers, six Baltimore City police officers, Howard County police officers, five Prince George's County police officers and five Montgomery County police officers.

Generally, the course and any refresher courses are offered on demand to a group of 24 to 30 participants. The curriculum comprises 40 hours of hazardous materials transportation enforcement and compliance instruction, 40 hours of motor carrier safety regulations and 40 hours of "hands on" training.

At present, the Maryland State Department of the Environment has the only U.S. Department of Transportation certified instructor for this course in Maryland. The course is taught with the assistance of the Maryland State Police.

\section{Principal Contact:}

Roland G. Fletcher

Administrator

Center for Radiological Health

Department of the Environment

2500 Broening Highway

Baltimore, Maryland 21224

(301) 631-3300 


\section{Mississippi}

\section{General Information}

\section{Transportation-Specific Training}

No transportation-specific training is offered within the state. However, state emergency response personnel from the Division of Radiological Health participate in several Federal Emergency Management Agency and U.S. Nuclear Regulatory Commission courses that address transportation within their curricula.

\section{Organizations Trained}

Personnel from the Division of Radiological Health receive the training offered by FEMA and NRC.

\section{Funding Sources}

No special funds for training are identified. Funding for FEMA courses is provided by the Emergency Management Training Fund.

\section{Course-Specific Information}

The Mississippi Emergency Management Agency offers three FEMA courses on radiological emergency response as described below. Funding for radiological emergency response training courses offered by and to personnel within the state is provided by FEMA and NRC.

\section{Fundamentals Course for Radiological Monitors}

The one and one-half day FCRM course is offered by the Mississippi Emergency Management Agency 12 to 15 times each year. Approximately 15 to 40 local police, fire, emergency medical services and rescue personnel attend each session. 
Fundamentals Course for Radiological Response Teams

The FCRRT is taught annually or semi-annually to local responders by the Mississippi Emergency Management Agency.

Fundamentals Course for Radiological Officers

The Mississippi Emergency Management Agency offers the Fundamentals Course for Radiological Officers upon request.

\section{Basic Health Physics}

Each member of the state radiological response team participates in a basic health physics course at Louisiana State University.

Principal Contact:

Eddie S. Fuente

Director

Division of Radiological Health

Department of Health

3150 Lawson Street

P.O. Box 1700

Jackson, Mississippi 39215-1700

(601) 354-6657 


\section{Missouri}

\section{General Information}

\section{Transportation-Specific Training}

While no transportation-specific radiological emergency response training is offered, state personnel in the Bureau of Radiological Health participate in federal agency-sponsored training courses that include transportation in their curricula. Among these is the Radiological Emergency Response Operations Course offered in Las Vegas. Nevada, by the Federal Emergency Management Agency and the U.S. Department of Energy. In addition, the State Emergency Management Agency offers several FEMA courses, such as the Fundamentals Course for Radiological Monitors and others summarized previously in this report.

\section{Organizations Trained}

State responders and local police, fire, emergency medical services and rescue personnel receive training provided by SEMA and FEMA.

\section{Funding Sources}

No special funding for training courses is identified. FEMA courses are paid for through the Emergency Management Training Fund.

Principal Contact:

Kenneth V. Miller

Chief

Bureau of Radiological Health

Department of Health

1730 E. Elm Street

P.O. Box 570

Jefferson City, Missouri 65102 


\section{North Carolina}

\section{General Information}

\section{Transportation-Specific Training}

Radiological transportation accidents are a subject in the Federal Emergency Management Agency's Fundamentals Course for Radiological Monitors.

\section{Organizations Trained}

The Fundamentals Course for Radiological Monitors is presented and/or available to all counties in the state and is offered to all emergency response agencies such as law enforcement, fire, emergency medical services and the state Department of Transportation.

\section{Funding Sources}

The state's radiological emergency response training is funded through the FEMA Comprehensive Cooperative Agreement, the Superfund Amendment and Reauthorization Act Title III Training Program and the utilities with fixed nuclear facilities.

\section{Course-Specific Information}

\section{Fundamentals Course for Radiological Monitors}

As noted on page four of this report, federal field courses are offered within the state and are taught by state emergency response personnel. For the state of North Carolina, approximately 1,500 people in the State Highway Patrol and 1,200 in the Department of Transportation receive this level of training. In addition, personnel from county sheriffs' departments and city and county volunteer and paid fire, rescue and police agencies participate in the course. The two-day, 12-hour training course is offered as requested with refresher training every four years. The course is taught by representatives of State Emergency 
Management, the State Highway Patrol, the State Department of Transportation and local emergency management agencies. Instructors from many other emergency services agencies also assist.

\section{Principal Contact:}

Johnny D. James

Radiation Emergency Coordinator

Radiation Protection Section

North Carolina Department of Human Resources

701 Barbour Drive

Raleigh, North Carolina 27603-2008

(919) 733-4283 


\section{Okiahoma}

\section{General Information}

\section{Transportation-Specific Training}

Transportation-specific information is included in radiological emergency response courses. The Oklahoma Sate Department of Health offers a course on Environmental Emergency Response Standardization, and the Department of Public Safety includes radioactive materials transportation training in its Highway Patrol Cadet Training.

\section{Organizations Trained}

Environmental Emergency Response Standardization is taught to approximately 150 locally-assigned environmental health personnel. An equal number of students represents city-county health departments in the Oklahoma City and Tulsa areas. A few State Department of Health personnel also attend.

All Highway Patrol troopers receive the radioactive materials transportation training either during cadet training or eariy in their careers.

\section{Funding Sources}

State tax funds are used to suppori the training programs.

\section{Course-Specific Information}

\section{Environmental Emergency Response Standardization}

This course provides fundamental information on the purposes and procedures for coping with radiological incidents. including transportation accidents. The course is not designed to prepare first responders for the technical activities associated with radiological emergency response. 
A small number of State Department of Health environmental health personnei have received this training. All environmental health personnel in the 75 county health departments and the two city-county health departments have been trained, totalling approximately 150 persons.

The two-day course has been offered seven times at various locations around the state. A condensed video version is available for use in training future employees.

The training is made available by the State Department of Health in association with the University of Oklahoma. Persons who take the course and pass the exam are eligible to receive credit toward a Master's degree in Environmental Health from the University of Oklahoma.

\section{Highway Patrol Trooper Cadet Training}

All Highway Patrol trooper cadets receive the cadet training course, which is offered by the State Department of Public Safety.

\section{Principal Contact:}

Pau! Brown

Direcior

Consumer Protection Service

Department of Health

P.O. Box 53551

Oklahoma City, Oklahoma 73152

(405) 271-5221 


\section{South Carolina}

\section{General Information}

\section{Transportation-Specific Training}

Courses that are either transportation-specific or that cover transportation accident response are offered by the U.S. Nuclear Regulatory Commission, the U.S. Depar ment of Transportation, the Federal Emergency Management Agency and the South Carolina Emergency Preparedness Division. The courses are as follows:

NRC - Nuclear Transportation for State Regulatory Personnel

DOT - Radioactive Material Transportation Workshop

FEMA - Radiological Emergency Response Course

SCEPD - Fundamentals Course for Radiological Response Teams

SCEPD - Fundamentals Course for Radiological Monitors

\section{Organizations Trained}

The South Carolina Department of Health and Environmental Control's Bureau of Radiological Health receives training from NRC, DOT and FEMA. The South Carolina Emergency Preparedness Division receives training from FEMA and provides training to state and local agencies.

In addition, Chem-Nuclear Systems, Inc., the operator of the low-level radioactive waste disposal facility in Barnwell, South Carolina, provides emergency response training to local fire and law enforcement departments in the Barnwell County area. The company offers transportation courses six times each year.

\section{Funding Sources}

Training is funded by FEMA, NRC and, on a limited basis, by the state. 


\section{Course-Specific Information}

\section{NRC - Nuclear Transportation for State Regulatory Personnel}

NRC offers this one-week comprehensive course dealing with federal regulations and guidelines for the transportation of radioactive material. Trainees include personnel in the Department of Health and Environmental Control's Bureau of Radiological Health and inspectors from the Division of Radioactive Materials Transportation Section. The course is offered twice each year in Columbia, South Carolina.

\section{DOT - Radioactive Material Transportation Workshop}

The curriculum of this DOT course is similar to that of the NRC training described above, and the trainees are the same. The one-week course is offered annually by DOT in Aiken, South Carolina.

\section{FEMA - Radiological Emergency Response Course}

The course provides classroom time devoted to basic concepts of health physics and radiation protection followed by field exercises devoted to accidents involving radiography, nuclear medicine, transportation and reactor operations. The entire staff of the Department of Health and Environmental Control's Bureau of Radiological Health, approximately 25 people, receive this training at a rate of three per year. Three individuals in the Emergency Preparedness Division are also trained yearly.

The course is offered twice each year and lasts for two weeks. FEMA is the agency responsible for instruction. The course is taught at the Emmitsburg, Maryland Training Center.

\section{Fundamentals Course for Radiological Response Teams}

This fundamentals course teaches basic radiation protection concepts for first responders to accidents involving radioactive material. Approximately 50 officers of the Highway Patrol and 30 officers of the Department of Wildlife and 
Marine Resources receive the training at the state level. Last year approximately 175 county and local emergency response personnel participated in the training. They represented city and county organizations near fixed nuclear facilities and within emergency planning zones.

The one-week course is offered as needed and is followed up with the Radiological Monitor Refresher Course and the Radiological Officer Refresher Course. The South Carolina Emergency Preparedness Division is the agency responsible for teaching the course. The course is taught at various locations throughout South Carolina.

\section{Principal Contact:}

Heyward G. Shealy

Chief

Bureau of Radiological Health

Department of Health and Environmental Control

2600 Bull Street

Columbia, South Carolina 29201

(803) 734-4700 


\section{Tennessee}

\section{General Information}

\section{Transportation-Specific Training}

The primary course for emergency response, the Federal Emergency Management Agency's Radiological Emergency Response Operations course in Las Vegas, Nevada, deals with transportation accidents along with fixed nuclear and fixed small facility response. Other courses, such as the Oak Ridge Associated Universities five-week course, teach the techniques of health physics that are applied to any emergency response.

\section{Organizations Trained}

All Division of Radiological Health personnel are sent to each of these courses as they are made available. Personnel from the division have recently attended two courses that deal with the regulatory aspects of shipping radioactive materials, one presented by SEG of Oak Ridge and another, Radioactive Materials Training Course on the Hazardous Materials Regulations of the U.S. Department of Transportation, taught by DOT.

Only Division of Radiological Health and Oak Ridge National Laboratory personnel participate in the five-week course at Oak Ridge. Personnel from the Division of Radiological Health and the Tennessee Emergency Management Agency participate in the RERO course in Las Vegas.

\section{Funding Sources}

In addition to the standard budgetary allotment, the state has a contract with the Tennessee Valley Authority for two planning positions. Part of the planners' jobs is to train division personnel for emergency response at TVA's fixed nuclear facilities. The courses are funded by various federal agencies, RERO by FEMA and the five-week course by NRC. These planners also teach a two-hour refresher course to local emergency response personnel for nuclear plant response, usually just before a FEMA-graded exercise. 


\section{Course-Specific Information}

Several FEMA courses are taught in Tennessee with assistance provided by the Division of Radiological Health. Attendees usually include first responders, firemen, police, ambulance personnel and paramedics. Much of the course curriculum addresses transportation accidents to the extent that first responders need to know how to stabilize an accident until help arrives.

The first three courses listed are taught in sequence. The courses are open to anyone who might want to attend and have been taught to state personnel from other divisions to acquaint them with radiation emergency response.

\section{Radiological Monitors Course}

The Radiological Monitors course is the first level in the FEMA civil defense series. The two-day course teaches the basics of meter reading. The Tennessee Emergency Management Agency and the Division of Radiological Health offer the course five to 10 times each year, as requested. Refresher courses are also available.

\section{Radiological Response Teams Course}

The RRT course instructs participants to perform simple health physics activities in the event of a nuclear incident, including a transportation accident. The one-week course is offered three to five times annually and is followed up with refresher courses. The Tennessee Emergency Management Agency and the Division of Radiological Health are responsible for instruction.

\section{Radiological Officers Course}

Management of a fallout shelter is the primary topic of the RO course. The one-week course is offered by the Tennessee Emergency Management Agency and the Division of Radiological Health once or twice a year. No refresher course is offered. 


\section{Hospital Emergency Room Operations}

This course teaches hospital personnel procedures for handling a contaminated patient. It is offered upon request once or twice each year. The Tennessee Emergency Management Agency and the Division of Radiological Health teach the course over a two-day period. No refresher course is offered.

\section{Principal Contact:}

Debra Shults

Superintendent Technical Services

Division of Radiological Health

Department of Health and Environment

Terra Building

150 9th Avenue, North

Nashville, Tennessee 37219-5404

(615) 741-7812 


\section{Texas}

\section{General Information}

\section{Transportation-Specific Training}

Transportation-specific training is incorporated into Federal Emergency Management Agency contracted, peacetime radiological emergency response courses.

\section{Organizations Trained}

State employees occasionally receive emergency response training, but the primary recipients are local fire departments, law enforcement officers and emergency medical services responders.

\section{Funding Sources}

The state's emergency response training is funded through contract with FEMA.

\section{Course-Specific Information}

\section{Radiological Response Team Course}

State employees occasionally participate in the RRT course. The primary participants are personnel from local fire departments, law enforcement agencies and emergency medical services. Approximately 40 individuals representing these organizations receive training each month. The 32-hour course, which is offered once each month, is followed up with refresher courses. The Texas Department of Health's Bureau of Emergency Management provides the instruction. 


\section{Radiological Officers Course}

As with the RRT course, this training is directed to local fire departments, law enforcement agencies and emergency medical services. Approximately 40 individuals are trained each month. This 32-hour training session is also offered once a month and is followed up with refresher courses. The Bureau of Emergency Management teaches the course.

\section{Radiological Monitoring Course}

The Radiological Monitoring course is offered to approximately 40 local fire, law enforcement and emergency medical services personnel each month. State employees will participate occasionally. The training, which is held monthly, lasts nine hours. A refresher course is available. The Bureau of Emergency Management provides the instruction.

\section{Principal Contact:}

David Lacker

Chief

Bureau of Radiation Control

Department of Health

1100 W. 49th Street

Austin, Texas 78756-3189

(512) 835-7000 


\section{Virginia}

\section{General Information}

\section{Transportation-Specific Training}

Transportation is taught as a portion under the Integrated Emergency Management System (IEMS). The IEMS training includes transportation, fixed nuclear facilities and war-caused damages.

\section{Organizations Trained}

Trainees include volunteer responders, mainly from fire departments, and hazardous materials officers with the Virginia Department of Emergency Services. Also, Regional Hazardous Materials Response Teams from specified fire departments are trained.

\section{Funding Sources}

The state's radiological emergency response training is supported with Federal Emergency Management Agency funds and matching state funds.

\section{Course-Specific Information}

\section{Fundamentals Course for Radiological Response Teams}

The fundamentals course curriculum covers concepts of radiation protection, radiation detection instruments and radiological monitoring techniques; nuclear weapons effects and protective actions; peacetime radioactive protective actions for first response functions; shelter monitoring; and basic decontamination procedures. 
At the state level, approximately nine individuals with the Department of Emergency Services receive this course. At the local level, fire department and safety personnel generally participate, although the course is available to any interested party.

Depending on demand, the training is offered once or twice each year. The three-day course, which is taught by the Department of Emergency Services, is followed up with refresher courses.

\section{Principal Contact:}

Leslie P. Foldesi

Director

Bureau of Radiological Health

Department of Health

109 Governor Street

Richmond, Virginia 23219

(804) 786-5932 


\section{West Virginia}

\section{General Information}

\section{Transportation-Specific Training}

State personnel receive transportation-specific emergency response training from the U.S. Department of Energy through the transportation seminars it offers around the country.

\section{Organizations Trained}

Approximately 710 state and local personnel receive training from the Office of Emergency Services as well as several federal agencies. Several Federal Emergency Management Agency-recognized courses are taught to local responders by the Office of Emergency Services, while state radiological emergency response personnel participate in the Radiological Emergency Response Operations Course taught by FEMA and the U.S. Department of Energy in Las Vegas, Nevada, and other FEMA courses in Emmitsburg, Maryland.

\section{Funding Sources}

No special state funding for training courses was identified. FEMA courses are funded through the Emergency Management Training Fund.

\section{Course-Specific Information}

\section{Fundamentals Course for Radiological Monitors}

The West Virginia Office of Emergency Services provides the FCRM to local emergency responders each year in 12 counties around the state. The training is followed up with a refresher course. The Radiological Monitor Instructor Course is also taught by OES. 


\section{Fundamentals Course for Radiological Response Teams}

The RRT course is taught by the Office of Emergency Services once or twice each year to local fire, police, emergency medical services and rescue personnel. A refresher course is also offered.

\section{Fundamentals Course for Radiological Officers}

The Office of Emergency Services offers this management course once or twice each year to local radiological emergency responders.

\section{Principal Contact:}

Beattie DeBord

Chief Radiological Health Specialist

Industrial Hygiene Division

Department of Health

15111 th Avenue

Charleston, West Virginia 25303

(304) 348-3526 


\section{CONCLUSION}

This training course summary provides besic information about efforts to prepare state and locai personnel for response to a radiological emergency. The federal government. Lirough the Federal Emergency Manage!nent Agency, the U.S Department of Energy and the U.S. Nuclear Regulatory Commission, provides most of the training courses used by the states. Several FEMA courses that teach response fundamentals are offered in each state by the state emergency management agency. In addition, each state sends personnel to federal agency courses at the Nevada Test Site near Las Vegas, Nevada, and the National Emergency Training Center at Emmitsburg, Maryland. State training, therefore. is standardized by the availability of federal courses, and few differences exist between and among state training programs.

Almost all of the states in the SSEB region have nuclear power plants within their borders and, hence, their training programs, through the use of federal courses, iocus on fixed facility rerponse. Six states that responded to our survey. however. noted that transportation-specific training is included in their curricula. Arkansas, Florida, Maryland, Oklahoma. South Carolina and West Virginia described courses that concentrated solely on responding to a radiological transportation emergency. while other states listed transportation among the topics addressed in general radiological emergency response courses For additional infumation on transportation-specific training, the reader is directed to the state contacts provided in this report. 

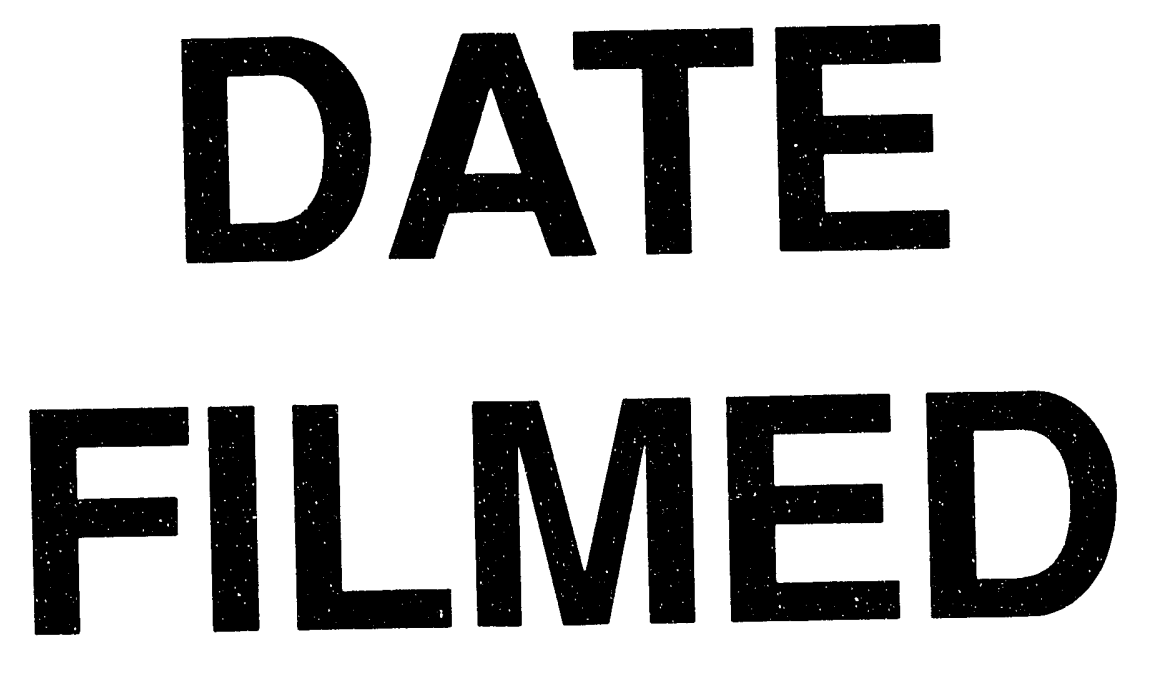

$$
7 / 27 / 93
$$
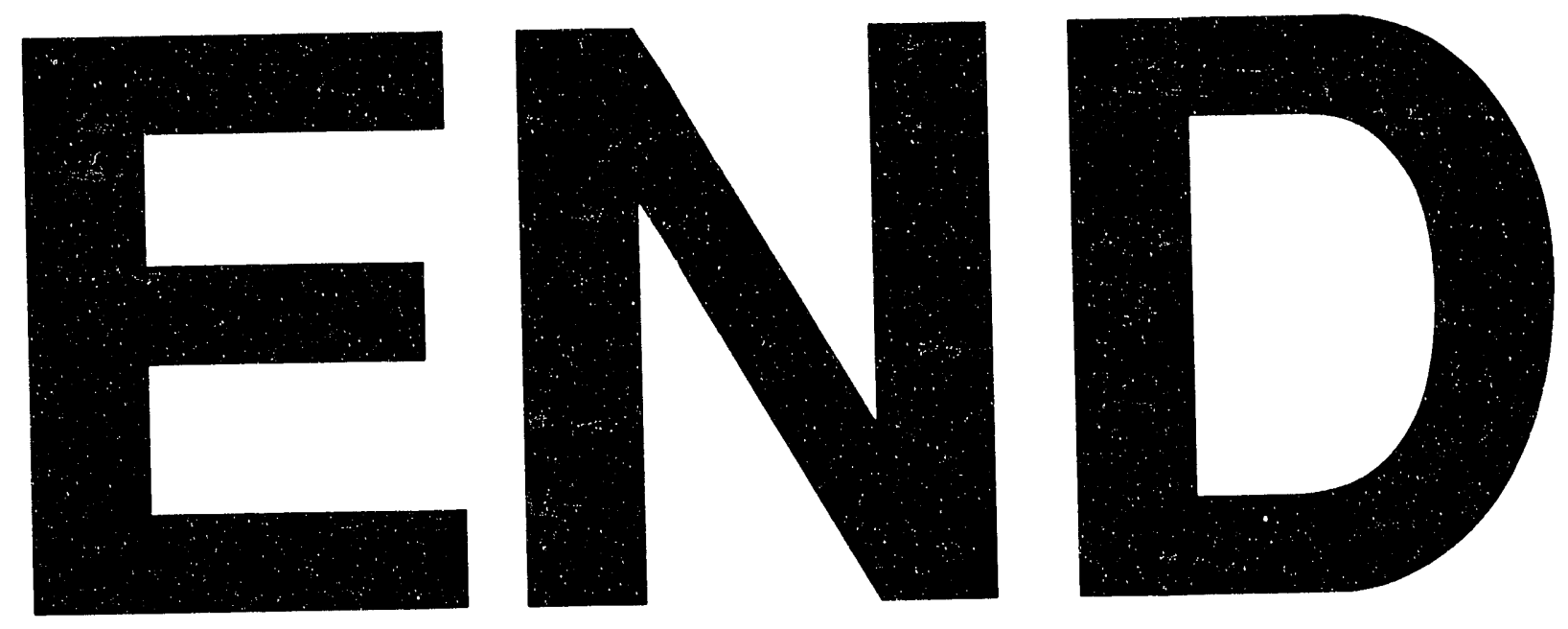
